The Effect Of E-Service Quality And Promotion On Customer Satisfaction On Grabfood Services

\title{
Pengaruh E-Service Quality Dan Promosi Terhadap Kepuasan Pelanggan Pada Layanan Grabfood
}

\author{
Rofidah Suhailah Sajidah ${ }^{1}$, Pramitha Aulia ${ }^{2}$ \\ ${ }^{1}$ Prodi S1 Administrasi Bisnis, Fakultas Komunikasi dan Bisnis, Universitas Telkom \\ ${ }^{2}$ Dosen Fakultas Komunikasi dan Bisnis, Universitas Telkom \\ Email: ${ }^{1}$ rofidahsuhailah@student.telkomuniversity.ac.id , ${ }^{2}$ mithpsy@telkomuniversity.ac.id
}

\begin{abstract}
This study aims to determine the application of e-service quality and promotions and its impact on customer satisfaction on the GrabFood services. This research uses quantitative methods with descriptive and causal types. The measurement scale used is the likert scale. The sample in this study were 100 respondents who are using GrabFood in Indonesia who were selected by purposive sampling technique. The data analysis technique is multiple linear regression using SPSS software ver. 25. The results show that the variable e-service quality and promotion, either partially or simultaneously, has a positive and significant impact on customer satisfaction on GrabFood services. Based on the results of the coefficient of determination, it is known that the effect of E-Service Quality and Promotion on Customer Satisfaction at GrabFood services is $61.9 \%$ and the remaining $38.1 \%$ is influenced by other variabels not examined in this study.
\end{abstract}

Keywords: E-Service Quality, Promotion, Customer Satisfaction.

\begin{abstract}
ABSTRAK
Penelitian ini bertujuan untuk mengetahui penerapan e-service quality dan promosi yang terdapat pada layanan GrabFood serta dampaknya terhadap kepuasan pelanggan pada layanan GrabFood. Penelitian ini menggunakan metode kuantitatif dengan jenis deskriptif dan kausal. Adapun skala pengukuran yang digunakan adalah skala likert. Sampel dalam penelitian ini diperoleh sebanyak 100 orang yang merupakan pengguna layanan GrabFood di Indonesia yang dipilih dengan teknik purposive sampling. Teknik analisis data yang digunakan adalah teknik analisis regresi linear berganda dengan bantuan software SPSS ver. 25. Hasil penelitian menunjukkan bahwa variabel e-service quality dan promosi, baik secara parsial maupun simultan memiliki pengaruh yang positif dan signifikan terhadap kepuasan pelanggan pada layanan GrabFood. Berdasarkan hasil uji koefisien determinasi, diketahui pengaruh e-service quality dan promosi terhadap kepuasan pelanggan pada layanan GrabFood sebesar $61,9 \%$ dan sisanya sebesar 38,1\% dipengaruhi oleh variabel lain yang tidak diteliti dalam penelitian ini.
\end{abstract}

Kata Kunci: E-Service Quality, Promosi, Kepuasan Pelanggan.

\section{PENDAHULUAN}

Perkembangan teknologi yang semakin pesat menyebabkan teknologi berperan sangat penting dalam kehidupan masyarakat. Salah satu manfaat dari kemajuan teknologi yang dirasakan oleh masyarakat saat ini adalah adanya digitalisasi. Dengan adanya digitalisasi, berbagai aktivitas yang sebelumnya dilakukan secara konvensional berubah menjadi digital, seperti dalam hal transportasi, belanja, transaksi, hiburan, perbankan dan lain-lain. Seluruh aktivitas tersebut menjadi lebih cepat dan mudah untuk dilakukan hanya dengan melalui aplikasi mobile yang tersedia pada smartphone yang dimiliki oleh masyarakat (Widiarini, 2020).

Adanya perkembangan layanan pesan-antar makanan daring (online food delivery) yang semakin populer di kalangan masyarakat Indonesia menjadi salah satu contoh digitalisasi saat ini. Data Momentum Works pada tahun 2020 menunjukkan bahwa Indonesia berhasil menjadi pemimpin pasar layanan online food delivery di Asia Tenggara dengan total nilai Gross Merchandise Value (GMV) sebesar US\$ 3,7 miliar. Di Indonesia sendiri, pasar layanan food delivery dipimpin oleh dua pemain besar, yaitu Gojek dengan Go-Food dan Grab dengan GrabFood. Hasil riset yang juga dilakukan oleh 
Momentum Works menunjukkan bahwa Grab dengan layanan GrabFood-nya berhasil memimpin pasar layanan pesan-antar makanan di lima negara di Asia Tenggara, termasuk salah satunya di Indonesia dengan menguasai 53\% atau sebesar US\$ 2 miliar dari total nilai Gross Merchandise Value (GMV), sementara Gojek dengan GoFood menguasai sebanyak 47\% atau sebesar US\$ 1,7 miliar (Jayani, 2021).

Prestasi yang diperoleh Grab membuktikan bahwa layanan GrabFood semakin diminati dan memiliki peluang pertumbuhan yang cukup besar di Indonesia. Dalam menghadapi ketatnya persaingan, Grab sebagai pemilik layanan GrabFood harus berupaya untuk mempertahankan posisinya saat ini supaya tidak tergeser oleh pesaingnya, yaitu Go-Food. Bagi perusahaan yang bergerak pada bidang jasa, upaya yang dapat dilakukan untuk mempertahankan kelangsungan perusahaan adalah dengan memberikan dan mempertahankan kepuasan pelanggan. Salah satu faktor yang dapat mempengaruhi kepuasan pelanggan adalah kualitas layanan.

Berdasarkan nilai rating aplikasi Grab yang diperoleh melalui Google Play Store, Grab memiliki rating sebesar 4.4, dimana hal ini membuktikan bahwa Grab memiliki kualitas layanan (e-service quality) yang sudah cukup baik. Selain e-service quality, promosi juga dapat berdampak terhadap kepuasan pelanggan karena promosi menjadi salah satu pertimbangan pelanggan dalam memutuskan untuk menggunakan sebuah layanan food delivery. Berdasarkan survei yang dilakukan oleh Statista pada tahun 2019 tentang Consumer Perception on Food Delivery Mobile App GrabFood Indonesia 2019, sebanyak 14,6 responden mengaitkan GrabFood dengan banyaknya promosi (Statista, 2019). Beberapa bentuk promosi pada layanan GrabFood diantaranya adalah melalui iklan di media sosial dan promosi penjualan yang terdapat pada aplikasi Grab maupun yang dikirimkan secara langsung melalui e-mail.

Namun, masih terdapat keluhan-keluhan yang diberikan oleh pelanggan terkait dengan e-service quality dan promosi pada layanan GrabFood, seperti pelanggan yang tidak menerima refund walaupun sudah melakukan komplain, kesulitan pelanggan dalam mengganti metode pembayaran, titik lokasi pelanggan yang tiba-tiba berubah ketika order sudah dilakukan, promo yang tidak bisa digunakan oleh pelanggan serta syarat dan ketentuan promo yang dianggap terlalu ribet oleh pelanggan, seperti kode promo hanya berlaku pada kota-kota besar saja serta syarat minimal pembelian yang sudah tercukupi tetapi promo masih tidak dapat digunakan.

Dengan adanya keluhan-keluhan tersebut, menyebabkan timbulnya ketidakpuasan yang dialami oleh pelanggan ketika menggunakan layanan GrabFood, dimana hasil dari e-service quality dan promosi yang diterima oleh pelanggan tidak sesuai dengan harapan pelanggan sehingga pelanggan pun merasa kecewa dan tidak puas terhadap layanan GrabFood. Hasil penelitian terdahulu yang dilakukan oleh Mediti (2020) menunjukkan bahwa e-service quality mampu mendorong terciptanya kepuasan pelanggan. Adanya produk atau jasa yang berkualitas dan memiliki spesifikasi yang sesuai dengan kebutuhan konsumen sehingga mampu menciptakan kepuasan bagi konsumen tersebut. Hal inilah yang mampu mendorong konsumen untuk merasakan kepuasan dari e-service quality yang diterima.Penelitian lainnya yang dilakukan oleh Faradina \& Satrio (2016) memperlihatkan pengaruh yang positif dan signifikan antara variabel promosi terhadap kepuasan pelanggan bahwa semakin baik dan semakin menarik promosi yang dilakukan oleh perusahaan, maka akan semakin tinggi pula kepuasan pelanggan.

Penelitian ini dilakukan di Indonesia karena melihat Indonesia merupakan pasar yang sangat potensial untuk perkembangan layanan GrabFood kedepannya serta belum adanya penelitian terdahulu yang meneliti tentang kepuasan pelanggan GrabFood di Indonesia. 


\section{TINJAUAN PUSTAKA}

\section{E-Service Quality}

Menurut Zeithaml et al., dalam Tjiptomo dan Chandra (2016:176), “E-Service Quality merupakan penilaian dan evaluasi secara keseluruhan dari keunggulan sebuah pengantar layanan elektronik di pasar virtual." Menurut Tjiptono \& Chandra (2016: 178), e-service quality dapat diukur dengan tujuh dimensi, yaitu efisiensi (efficiency), reliabilitas (reliability), pemenuhan (fulfillment), privasi (privacy), daya tanggap (responsiveness), kompensasi (compensation), kontak (contact).

\section{Promosi}

Menurut Malau (2017:103), promosi merupakan bentuk komunikasi pemasaran yang berusaha untuk menyebarluaskan informasi, mempengaruhi, membujuk, dan/atau mengingatkan sasaran pasar atas perusahaan dan produknya agar bersedia menerima, membeli, dan loyal kepada produk yang ditawarkan oleh perusahaan tersebut. Kotler dan Armstrong (2014) menjelaskan empat dimensi dalam promosi, yaitu periklanan (advertising), promosi penjualan (sales promotion), hubungan masyarakat (public relations), dan pemasaran langsung (direct marketing).

\section{Kepuasan Pelanggan}

Kepuasan Pelanggan menurut Kotler dan Keller (2016:153) merupakan sebuah perasaan senang atau kecewa seseorang yang diperoleh dengan cara membandingkan kinerja/hasil yang dirasakan dengan harapan. Adapun dimensi kepuasan pelanggan menurut Kotler dan Keller (2016:155), pelanggan dinyatakan puas maka: menggunakan jasa itu kembali, merekomendasikan jasa kepada orang lain, pelayanan sesuai yang diharapkan dan pelanggan tidak pernah mengeluh.

Menurut Engel et al. dalam (Priansa, 2017:197) mendefinisikan kepuasan pelanggan sebagai evaluasi purna beli dimana hasil dari alternatif yang dipilih sekurang-kurangnya adalah sama atau melebihi harapan pelanggan, sementara ketidakpuasan terjadi apabila hasil tersebut tidak dapat memenuhi harapan pelanggan.

\section{Hubungan E-Service Quality Terhadap Kepuasan Pelanggan}

Menurut Oliver dalam Tjiptono dan Chandra (2014:271), e-service quality merupakan bentuk dari servqual yang sangat berhubungan dengan kepuasan pelanggan yang umumnya didasarkan pada pendekatan diskonfirmasi dimana apabila kinerja suatu atribut (performance) lebih besar dibandingkan dengan harapan (expectations) untuk atribut tersebut, maka kepuasan dan kualitas jasa akan mengalami peningkatan.

Penelitian lainnya yang juga dilakukan oleh Mediti (2020), menunjukkan bahwa e-service quality memiliki pengaruh positif dan signifikan terhadap kepuasan pelanggan. Setiap produk atau jasa yang berkualitas, memiliki spesifikasi yang sesuai dengan kebutuhan konsumen sehingga mampu menciptakan kepuasan bagi konsumen tersebut. Hal inilah yang mampu mendorong konsumen untuk merasakan kepuasan dari e-service quality yang diterima.

\section{Hubungan Promosi Terhadap Kepuasan Pelanggan}

Menurut Cannon et al. dalam Faradina \& Satrio (2016), promosi merupakan bentuk komunikasi antara penjual dengan pembeli potensial yang bertujuan untuk mempengaruhi sikap dan perilaku (kepuasan pelanggan).

Penelitian yang dilakukan oleh Anugrah (2020) menunjukkan bahwa promosi memiliki pengaruh yang signifikan terhadap kepuasan pelanggan. Artinya, apabila promosi yang ditawarkan oleh perusahaan semakin baik dan menarik, maka akan menciptakan kepuasan pada pelanggan setelah melakukan transaksi. Akan tetapi, apabila promosi produk yang dilakukan oleh perusahaan terlalu luar 
biasa dan tidak sesuai dengan kenyataan, maka hal ini dapat menyebabkan ketidakpercayaan yang akan berdampak pada ketidakpuasan pelanggan" (Tjiptono dalam Vallery et al., 2020).

Berdasarkan teori-teori tersebut diatas, maka kerangka pemikiran pada penelitian ini adalah sebagai berikut.

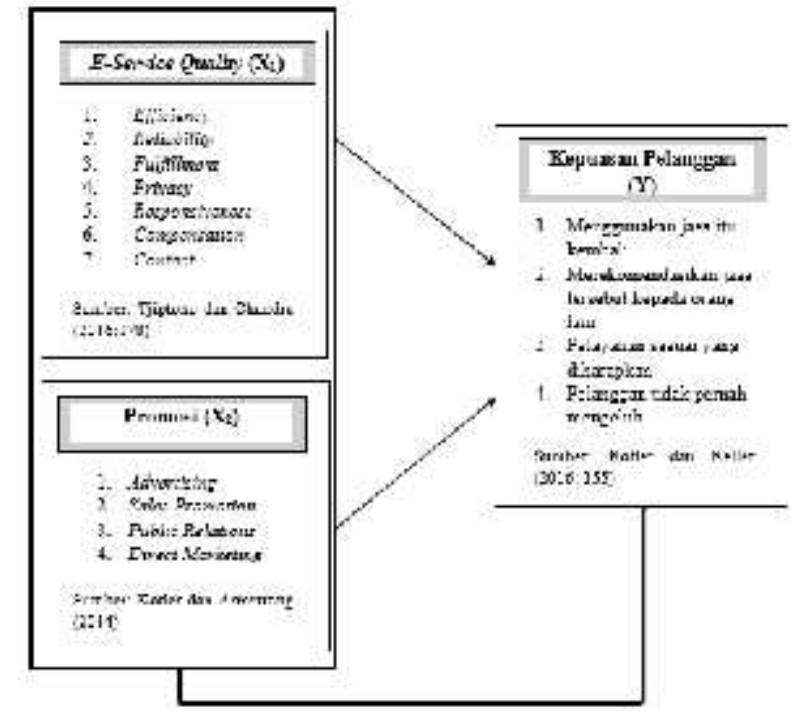

Gambar 1. Kerangka Pemikiran

Adapun hipotesis pada penelitian ini, yaitu "Terdapat Pengaruh dari E-Service Quality dan Promosi Secara Simultan dan Parsial Terhadap Kepuasan Pelanggan Layanan GrabFood".

\section{METODE}

Metode penelitian yang digunakan dalam penelitian ini adalah metode kuantitatif dengan jenis deskriptif dan kausal. Penelitian deskriptif bertujuan untuk menggambarkan karakteristik yang dimiliki oleh suatu kelompok tertentu (Indrawati, 2015:115), sedangkan penelitian kausal bertujuan untuk mengetahui hubungan sebab akibat yang dihasilkan oleh variabel independen sebagai variabel yang mempengaruhi dan variabel dependen sebagai variabel yang dipengaruhi (Sugiyono, 2014:37). Variabel independen dalam penelitian ini adalah E-Service Quality $\left(\mathrm{X}_{1}\right)$ dan Promosi $\left(\mathrm{X}_{2}\right)$, dan variabel dependen, yaitu Kepuasan Pelanggan (Y).

Populasi dalam penelitian ini adalah masyarakat di Indonesia yang telah mengunduh aplikasi Grab pada Play Store dan App Store serta menggunakan layanan GrabFood yang jumlahnya tidak diketahui secara pasti. Jumlah unduhan aplikasi Grab pada Google Play Store diketahui sebanyak 1 juta unduhan dimana jumlah yang besar ini tidak dapat digunakan sebagai populasi. Sementara pada App Store, jumlah unduhan aplikasi tidak ditampilkan oleh App Store. Oleh karena itu, jumlah populasi dalam penelitian ini tidak diketahui secara pasti. Teknik sampling yang digunakan adalah non probability sampling dengan jenis purposive sampling dan diperoleh jumlah sampel sebanyak 100 orang menggunakan rumus Bernoulli (Siregar, 2013:37).

Pengumpulan data dalam penelitian ini menggunakan data primer dan data sekunder. Data primer diperoleh dengan cara menyebarkan kuesioner secara online melalui Google Forms, sedangkan data sekunder diperoleh melalui jurnal nasional dan internasional, situs internet, serta penelitian terdahulu yang berhubungan dengan $e$-service quality, promosi dan kepuasan pelanggan. Teknik analisis data yang digunakan adalah analisis deskriptif, uji asumsi klasik, analisis regresi linear berganda, uji hipotesis (Uji-F dan Uji-T), serta koefisien determinasi yang diolah menggunakan software SPSS ver. 25 . 


\section{HASIL PENELITIAN \& PEMBAHASAN}

Analisis Deskriptif

Tabel 1. Hasil Analisis Deskriptif

\begin{tabular}{|c|c|c|c|}
\hline Variabel & Dimensi & Persentase & Kategori \\
\hline \multirow{7}{*}{$\begin{array}{c}\text { E-Service } \\
\text { Quality }\end{array}$} & Efficiency & $83,25 \%$ & Baik \\
\hline & Reliability & $71,25 \%$ & Baik \\
\hline & Fulfillment & $79,8 \%$ & Baik \\
\hline & Privacy & $82,4 \%$ & Baik \\
\hline & Responsiveness & $\mathbf{7 6 , 7 5 \%}$ & Baik \\
\hline & Compensation & $75,6 \%$ & Baik \\
\hline & Contact & $79,5 \%$ & Baik \\
\hline \multirow{4}{*}{ Promosi } & Advertising & $\mathbf{7 8 , 5 5 \%}$ & Baik \\
\hline & Sales Promotion & $79,92 \%$ & Baik \\
\hline & Public Relations & $71,12 \%$ & Baik \\
\hline & Direct Marketing & $70,06 \%$ & Baik \\
\hline \multirow{4}{*}{$\begin{array}{l}\text { Kepuasan } \\
\text { Pelanggan }\end{array}$} & Menggunakan Jasa Itu Kembali & $72,15 \%$ & Baik \\
\hline & $\begin{array}{c}\text { Merekomendasikan Jasa } \\
\text { Kepada Orang Lain }\end{array}$ & $69,8 \%$ & Baik \\
\hline & $\begin{array}{c}\text { Pelayanan Sesuai yang } \\
\text { Diharapkan }\end{array}$ & $73 \%$ & Baik \\
\hline & $\begin{array}{c}\text { Pelanggan Tidak Pernah } \\
\text { Mengeluh }\end{array}$ & $75,2 \%$ & Baik \\
\hline
\end{tabular}

Hasil analisis deskriptif pada tabel 1 diatas menunjukkan bahwa secara keseluruhan dimensi dari masing-masing variabel E-Service Quality $\left(\mathrm{X}_{1}\right)$ Promosi $\left(\mathrm{X}_{2}\right)$ dan Kepuasan Pelanggan (Y) termasuk dalam kategori baik.

\section{Uji Asumsi Klasik}

\section{a. Uji Normalitas}

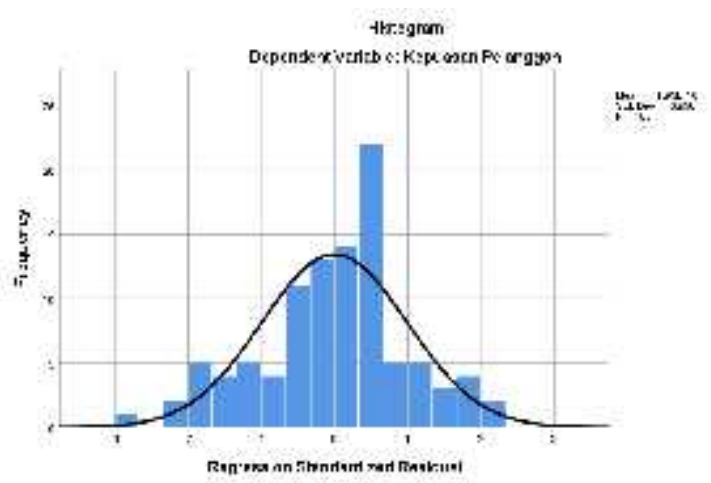

Gambar 1. Histogram

Berdasarkan gambar diatas, hasil grafik histogram menunjukkan pola lonceng dan tidak miring ke kiri dan ke kanan sehingga dapat disimpulkan bahwa data berdistribusi normal. 


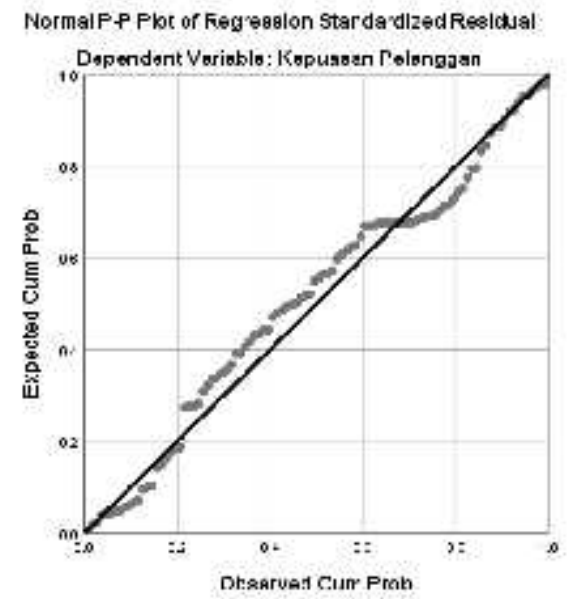

Gambar 2. Grafik Normal Probability Plot

Gambar 2 diatas menunjukkan bahwa data berdistribusi normal karena persebaran data yang berada di sekitar garis diagonal serta mengikuti arah garis diagonal.

Tabel 2. Tabel Kolmogorov-Smirnov Test

\begin{tabular}{|c|c|c|}
\hline \multicolumn{3}{|c|}{ One-Sample Kolmogorov-Smirnov Test } \\
\hline & & \multirow{2}{*}{$\begin{array}{c}\text { Unstandardized } \\
\text { Residual }\end{array}$} \\
\hline & & \\
\hline $\mathrm{N}$ & & 100 \\
\hline \multirow[t]{2}{*}{ Normal Parameters ${ }^{a, b}$} & Mean & .0000000 \\
\hline & Std. Deviation & 4.67316509 \\
\hline \multirow[t]{3}{*}{ Most Extreme Differences } & Absolute & .074 \\
\hline & Positive & .074 \\
\hline & Negative & -.071 \\
\hline Test Statistic & & .074 \\
\hline Asymp. Sig. (2-tailed) & & $.200^{\mathrm{c}, \mathrm{d}}$ \\
\hline \multicolumn{3}{|c|}{$\begin{array}{l}\text { a. Test distribution is Normal. } \\
\text { b. Calculated from data. } \\
\text { c. Lilliefors Significance Correction. } \\
\text { d. This is a lower bound of the true significance. }\end{array}$} \\
\hline
\end{tabular}

Pada diatas, terlihat bahwa nilai Asymp. Sig. (2 tailed) adalah 0,200 dimana nilai ini diatas nilai signifikansi $(0,05)$, dengan kata lain variabel residual berdistribusi normal.

b. Uji Multikolinearitas

Tabel 3. Hasil Uji Multikolinearitas

\begin{tabular}{|c|c|c|c|c|c|c|}
\hline \multicolumn{7}{|c|}{ Coefficientsa } \\
\hline \multirow{2}{*}{ Model } & \multicolumn{2}{|c|}{$\begin{array}{l}\text { Unstandardized } \\
\text { Coefficients }\end{array}$} & \multirow{2}{*}{\multicolumn{2}{|c|}{$\begin{array}{c}\text { Standardized } \\
\text { Coefficients } \\
\text { Beta }\end{array}$}} & \multicolumn{2}{|c|}{$\begin{array}{l}\text { Collinearity } \\
\text { Statistics }\end{array}$} \\
\hline & B & $\begin{array}{l}\text { Std. } \\
\text { Error }\end{array}$ & & & Tolerance & VIF \\
\hline \multirow[t]{3}{*}{1} & (Constant) & -1.263 & 2.889 & & & \\
\hline & $\begin{array}{l}\text { E-Service } \\
\text { Quality }\end{array}$ & . 156 & .060 & .257 & .400 & 2.500 \\
\hline & Promosi & .389 & .068 & .571 & .400 & 2.500 \\
\hline
\end{tabular}


Pada tabel diatas, diperoleh nilai Variance Inflation Factor (VIF) sebesar 2,500 < 10 dan nilai Tolerance sebesar 0,4>0,1, sehingga dapat diartikan dalam penelitian ini tidak ditemukan adanya masalah multikolinearitas.

\section{c. Uji Heteroskedastisitas}

\section{1) Grafik Scatterplot}

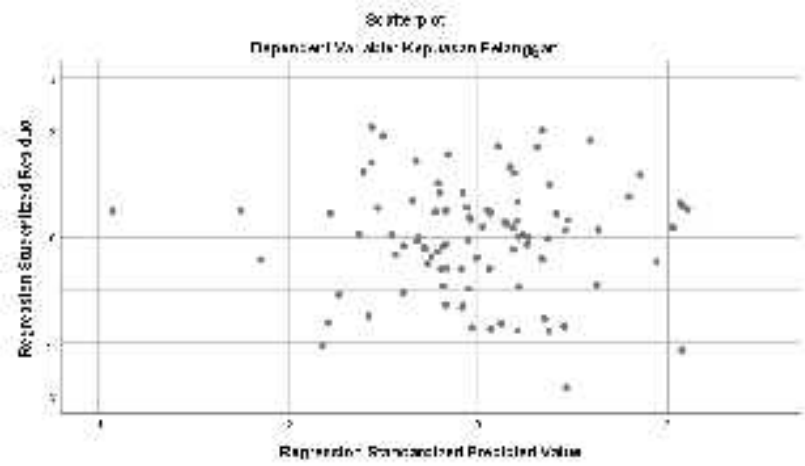

Gambar 3. Diagram Pencar (Scatterplot)

Dapat dilihat pada gambar 3, diketahui tidak terdapat pola tertentu pada diagram pencar Scatterplot, sehingga dapat disimpulkan tidak terjadi masalah heteroskedastisitas pada penelitian ini.

\section{2) Uji Glejser}

Tabel 4. Uji Heteroskedastisitas Dengan Uji Glejser

\begin{tabular}{|c|c|c|c|c|c|c|}
\hline \multicolumn{7}{|c|}{ Coefficients $^{a}$} \\
\hline \multirow{2}{*}{\multicolumn{2}{|c|}{ Model }} & \multicolumn{2}{|c|}{$\begin{array}{l}\text { Unstandardized } \\
\text { Coefficients }\end{array}$} & \multirow{2}{*}{$\begin{array}{c}\text { Standardized } \\
\text { Coefficients } \\
\text { Beta }\end{array}$} & \multirow[t]{2}{*}{$\mathbf{t}$} & \multirow[t]{2}{*}{ Sig. } \\
\hline & & B & Std. Error & & & \\
\hline \multirow[t]{3}{*}{1} & (Constant) & 2.955 & 1.808 & & 1.635 & .105 \\
\hline & E-Service Quality & .011 & .038 & .045 & .282 & .778 \\
\hline & Promosi & -.002 & .042 & -.008 & -.050 & .960 \\
\hline
\end{tabular}

a. Dependent Variabel: Abs_Res

Dari tabel 4 diatas, dapat dilihat hasil uji heteroskedastisitas menggunakan uji glejser dan diperoleh hasil signifikansi pada setiap variabel independen $>0.05$, sehingga dapat disimpulkan tidak adanya masalah heteroskedastisitas pada penelitian ini.

\section{Analisis Regresi Linear Berganda}

Tabel 5. Hasil Uji Regresi Linear Berganda

\begin{tabular}{|c|c|c|c|c|c|c|}
\hline \multicolumn{7}{|c|}{ Coefficients ${ }^{a}$} \\
\hline \multirow{2}{*}{\multicolumn{2}{|c|}{ Model }} & \multicolumn{2}{|c|}{$\begin{array}{l}\text { Unstandardized } \\
\text { Coefficients }\end{array}$} & \multirow{2}{*}{$\begin{array}{c}\begin{array}{c}\text { Standardized } \\
\text { Coefficients }\end{array} \\
\text { B eta }\end{array}$} & \multirow[t]{2}{*}{$\mathbf{t}$} & \multirow[t]{2}{*}{ Sig. } \\
\hline & & B & Std. Error & & & \\
\hline \multirow[t]{3}{*}{1} & (Constant) & -1.263 & 2.889 & & -437 & .663 \\
\hline & $\begin{array}{l}\text { E-Service } \\
\text { Quality }\end{array}$ & .156 & .060 & .257 & 2.590 & .011 \\
\hline & Promosi & .389 & .068 & .571 & 5.754 & .000 \\
\hline
\end{tabular}


Tabel 5 diatas menunjukkan hasil uji regresi linear berganda dengan model persamaan regresi yang dapat dinyatakan sebagai berikut:

$$
\begin{gathered}
\mathrm{Y}=\mathrm{a}+h_{1} X_{1}+h_{9} X_{2} \\
\mathbf{Y = \mathbf { - 1 , 2 6 3 }}+\mathbf{0 , 1 5 6} \mathbf{X}_{\mathbf{1}}+\mathbf{0 , 3 8 9} \mathbf{X}_{\mathbf{2}}
\end{gathered}
$$

Berdasarkan persamaan diatas, maka dapat dijelaskan sebagai berikut:

1) Konstanta (a) $=-1.263$ bernilai negatif, artinya apabila tidak terdapat variabel independen $E$ Service Quality $\left(\mathrm{X}_{1}\right)$ dan Promosi $\left(\mathrm{X}_{2}\right)$ atau kedua variabel tersebut bernilai nol, maka variabel Kepuasan Pelanggan (Y) bernilai sama dengan konstanta, yaitu sebesar -1.263. Nilai konstanta negatif dapat diartikan apabila variabel $\mathrm{X}$ tidak ada, maka nilai variabel $\mathrm{Y}$ akan mengalami penurunan. Hal ini berindikasi bahwa variabel $\mathrm{X}$ memiliki pengaruh yang besar terhadap variabel Y.

2) Nilai positif dari koefisien regresi variabel e-service quality $\left(b_{1}\right)$ sebesar 0,156 artinya setiap terjadi peningkatan e-service quality sebesar satu satuan, maka kepuasan pelanggan akan meningkatkan sebesar 0,156 .

3) Nilai positif dari koefisien regresi variabel promosi $\left(b_{2}\right)$ sebesar 0,389 artinya setiap terjadi peningkatan promosi sebesar satu satuan, maka kepuasan pelanggan akan meningkatkan sebesar 0,389 .

Berdasarkan persamaan tersebut, diketahui variabel e-service quality dan promosi memiliki pengaruh positif dan signifikan terhadap variabel kepuasan pelanggan. Artinya, apabila variabel $e$ service quality dan promosi ditingkatkan, maka dapat meningkatkan kepuasan pelanggan.

\section{Uji Hipotesis}

\section{a. Uji Simultan (Uji-F)}

\begin{tabular}{|c|c|c|c|c|c|c|}
\hline \multicolumn{7}{|c|}{ ANOVA $^{a}$} \\
\hline \multicolumn{2}{|r|}{ Model } & $\begin{array}{l}\text { Sum of } \\
\text { Squares }\end{array}$ & df & Mean Square & $\mathbf{F}$ & Sig. \\
\hline \multirow[t]{3}{*}{1} & Regression & 3506.482 & 2 & 1753.241 & 78.660 & $.000^{\mathrm{k}}$ \\
\hline & Residual & 2162.009 & 97 & 22.289 & & \\
\hline & Total & 5668.491 & 99 & & & \\
\hline
\end{tabular}

Tabel 6. Hasil Uji-F

Berdasarkan tabel 6 dapat diketahui F-hitung > F-tabel $(78,660>3,09)$ dengan signifikansi $0,000<0,05$, sehingga dapat dinyatakan $\mathrm{H}_{0}$ ditolak dan $\mathrm{H}_{\mathrm{a}}$ diterima. Artinya, variabel E-Service Quality $\left(\mathrm{X}_{1}\right)$ dan Promosi $\left(\mathrm{X}_{2}\right)$ secara bersama-sama berpengaruh signifikan terhadap Kepuasan Pelanggan pada layanan GrabFood.

\section{b. Uji Parsial (Uji-T)}

\begin{tabular}{|c|c|c|c|c|c|c|}
\hline \multicolumn{7}{|c|}{ Coefficients $^{a}$} \\
\hline & \multirow[t]{2}{*}{ Model } & \multicolumn{2}{|c|}{$\begin{array}{l}\text { Unstandardized } \\
\text { Coefficients }\end{array}$} & \multirow{2}{*}{$\begin{array}{c}\begin{array}{c}\text { Standardized } \\
\text { Coefficients }\end{array} \\
\text { B eta } \\
\end{array}$} & \multirow[t]{2}{*}{$\mathbf{t}$} & \multirow[t]{2}{*}{ Sig. } \\
\hline & & B & Std. Error & & & \\
\hline \multirow[t]{3}{*}{1} & (Constant) & -1.263 & 2.889 & & -437 & .663 \\
\hline & E-Service Quality & .156 & .060 & .257 & 2.590 & .011 \\
\hline & Promosi & .389 & .068 & .571 & 5.754 & .000 \\
\hline
\end{tabular}

Tabel 7. Hasil Uji-T 
Berdasarkan tabel 7 di atas, diketahui bahwa:

1. Variabel e-service quality $\left(\mathrm{X}_{1}\right)$ dengan nilai t-hitung sebesar $(2,590)>\mathrm{t}$-tabel $(1,985)$ dengan nilai signifikansi $0,011<0,05$, sehingga dapat diartikan bahwa $\mathrm{H}_{0}$ ditolak dan $\mathrm{H}_{\mathrm{a}}$ diterima. Dengan kata lain, secara parsial terdapat pengaruh yang signifikan antara variabel $e$-service quality $\left(\mathrm{X}_{1}\right)$ terhadap kepuasan pelanggan (Y).

2. Variabel promosi $\left(\mathrm{X}_{2}\right)$ dengan nilai t-hitung sebesar $(5,754)>\mathrm{t}$-tabel $(1,985)$ dengan nilai signifikansi $0,000<0,05$, sehingga dapat diartikan bahwa $\mathrm{H}_{0}$ ditolak dan $\mathrm{H}_{\mathrm{a}}$ diterima. Dengan kata lain, secara parsial terdapat pengaruh yang signifikan antara variabel promosi $\left(\mathrm{X}_{2}\right)$ terhadap kepuasan pelanggan (Y).

\section{Koefisien Determinasi}

Tabel 8. Tabel uji koefisien determinasi

\begin{tabular}{|c|c|c|c|c|}
\hline \multicolumn{5}{|c|}{ Model Summary } \\
\hline Model & $\mathbf{R}$ & R Square & Adjusted R Square & $\begin{array}{c}\text { Std. Error of the } \\
\text { Estimate }\end{array}$ \\
\hline 1 & $.787^{\mathrm{a}}$ & .619 & .611 & 4.721096 \\
\hline \multicolumn{5}{|c|}{ a. Predictors: (Constant), Promosi, E-Service Quality } \\
\hline \multicolumn{5}{|c|}{ b. Dependent Variabel: Kepuasan Pelanggan } \\
\hline
\end{tabular}

Tabel 8 diatas memperlihatkan besar nilai $\mathrm{R}$ adalah 0,787 dan $\mathrm{R}$ square $\left(\mathrm{R}^{2}\right)$ adalah 0,619. Hasil tersebut dipergunakan untuk melihat seberapa besar pengaruh simultan e-service quality dan promosi terhadap kepuasan pelanggan dengan menggunakan rumus koefisien determinasi (KD) sebagai berikut.

$$
\begin{gathered}
\mathrm{KD}=\mathrm{r}^{2} \times 100 \% \\
=(0,619)^{2} \times 100 \%=61,9 \%
\end{gathered}
$$

Hasil uji koefisien determinasi tersebut menunjukkan bahwa pengaruh variabel e-service quality dan promosi terhadap kepuasan pelanggan sebesar 61,9\% dan sisanya, 38,1\% dipengaruhi oleh variabel lain yang tidak diteliti dalam penelitian ini.

\section{PEMBAHASAN}

\section{Analisis Tanggapan Responden Terhadap Variabel E-Service Quality Pada Layanan GrabFood}

Hasil analisis deskriptif yang diperoleh terkait tanggapan responden terhadap seluruh dimensi variabel e-service quality, yaitu efficiency, reliability, fulfillment, privacy, responsiveness, dan contact termasuk dalam kategori baik. Dimensi yang mendapatkan tanggapan responden paling tinggi adalah dimensi efficiency dengan nilai persentase sebesar 83,25\% dan termasuk dalam kategori baik. Pada dimensi tersebut, pernyataan yang mendapatkan tanggapan responden paling tinggi adalah layanan GrabFood mudah digunakan dengan persentase sebesar 86,8\% dan termasuk dalam ketegori sangat baik. Artinya, bahwa layanan GrabFood sangat ramah pengguna. Adanya tampilan dan fitur-fitur pada layanan GrabFood yang mudah dipahami oleh pengguna membuat pengguna tidak merasa kesulitan ketika mengunakan layanan GrabFood.

Sedangkan dimensi yang mendapatkan tanggapan paling rendah, yaitu dimensi reliability dengan nilai persentase sebesar $71,25 \%$ dan termasuk dalam kategori baik. Adapun pernyataan yang mendapatkan tanggapan paling rendah adalah layanan GrabFood tidak pernah mengalami error saat digunakan dengan persentase sebesar 65,2\% dan termasuk dalam kategori cukup baik. Artinya, masih terdapat masalah-masalah yang menjadi penyebab error pada layanan GrabFood. Beberapa masalah 
error yang dialami oleh pengguna diantaranya adalah titik lokasi pelanggan yang tidak akurat dan sering berubah-ubah, pelanggan tidak bisa menghubungi driver melalui fitur chat, dan pelanggan kesulitan memilih metode pembayaran.

\section{Analisis Tanggapan Responden Terhadap Variabel Promosi Pada Layanan GrabFood}

Hasil analisis deskriptif pada variabel promosi dengan dimensi advertising, sales promotion, public relations, dan direct marketing secara keseluruhan berada pada kategori baik. Dimensi yang mendapatkan tanggapan responden paling tinggi adalah dimensi sales promotion dengan nilai persentase sebesar 79,92\% dan termasuk dalam kategori baik. Pada dimensi tersebut, pernyataan yang mendapatkan tanggapan responden paling tinggi adalah GrabFood memberikan poin setelah pesanan pelanggan selesai dilakukan dengan persentase sebesar $81,8 \%$ dan termasuk dalam ketegori baik. Artinya, GrabFood selalu memberikan akumulasi poin setelah pelanggan selesai melakukan pemesanan makanan. Adapun bentuk akumulasi poin yang diberikan biasanya dalam bentuk OVOPoints.

Sedangkan dimensi yang mendapatkan tanggapan paling rendah, yaitu dimensi direct marketing dengan nilai persentase sebesar $64 \%$ dan termasuk dalam kategori cukup baik. Adapun pernyataan yang mendapatkan tanggapan paling rendah adalah saya memperoleh informasi mengenai GrabFood secara langsung melalui e-mail dan saya memperoleh informasi mengenai GrabFood melalui akun Instagram GrabFood. Artinya, promosi secara langsung yang dilakukan oleh GrabFood melalui e-mail dan akun Instagram GrabFood belum efektif untuk digunakan sebagai media untuk menyampaikan informasi GrabFood kepada pelanggan. Hal ini dikarenakan tidak semua pelanggan GrabFood membuka/membaca e-mail setiap hari dan tidak semua pelanggan GrabFood mengikuti akun Instagram GrabFood.

\section{Analisis Tanggapan Responden Terhadap Variabel Kepuasan Pelanggan Pada Layanan GrabFood}

Hasil analisis deskriptif untuk masing-masing dimensi variabel kepuasan pelanggan secara keseluruhan berada pada ketogori baik. Dimensi yang mendapatkan tanggapan responden paling tinggi adalah dimensi pelanggan tidak pernah mengeluh dengan nilai persentase sebesar 75,2\% dan termasuk dalam kategori baik. Pada dimensi tersebut, pernyataan yang mendapatkan tanggapan responden paling tinggi adalah saya merasa puas setelah mendapatkan jasa yang diberikan GrabFood dengan persentase sebesar 78,4\% dan termasuk dalam ketegori baik. Artinya, GrabFood sudah cukup berhasil dalam memberikan kepuasan ketika pelanggan menggunakan layanan GrabFood.

Sedangkan dimensi yang mendapatkan tanggapan paling rendah, yaitu dimensi merekomendasikan jasa kepada orang lain dengan nilai persentase sebesar 69,8\% dan termasuk dalam kategori baik. Adapun pernyataan yang mendapatkan tanggapan paling rendah adalah saya tidak akan merekomendasikan layanan food delivery selain GrabFood kepada orang lain. Artinya, konsumen yang menggunakan layanan GrabFood masih merasakan ketidakpuasan saat menggunakan layanan tersebut sehingga konsumen sewaktu-waktu akan merekomendasikan kepada orang lain untuk menggunakan layanan food delivery yang lebih baik dibandingkan dengan GrabFood.

\section{Analisis Pengaruh E-Service Quality Terhadap Kepuasan Pelanggan Pada Layanan GrabFood}

Berdasarkan hasil uji hipotesis secara parsial (Uji-T), variabel e-service quality yang memiliki nilai t-hitung > t-tabel $(2,590>1,985)$ dengan nilai signifikansi $(0,011<0,05)$, maka dapat disimpulkan bahwa variabel e-service quality memiliki pengaruh yang signifikan terhadap kepuasan pelanggan pada layanan GrabFood. Artinya, semakin baik kualitas layanan GrabFood, maka kepuasan pelanggan pun akan semakin meningkat. Melalui e-service quality, GrabFood telah memberikan kemudahan bagi pelanggan dalam memesan makanan, diantaranya kemudahan dalam menggunakan layanan, kemudahan memperoleh informasi dan produk, kecepatan mengakses layanan, akurasi janji layanan, kemampuan 
melindungi informasi pelanggan, pemberian kompensasi serta tersedianya kontak yang dapat dihubungi oleh pelanggan ketika terjadi masalah. Kemudahan yang diberikan melalui kualitas layanan GrabFood mampu menciptakan pengalaman positif ketika pelanggan menggunakan layanan GrabFood sehingga pelanggan merasa puas. Hal ini membuktikan bahwa adanya kesesuaian antara kinerja yang dirasakan dengan harapan pelanggan, sehingga tercipta kepuasan pelanggan.

\section{Analisis Pengaruh Promosi Terhadap Kepuasan Pelanggan Pada Layanan GrabFood}

Berdasarkan hasil Uji-T untuk variabel promosi, diperoleh nilai t-hitung > t-tabel $(5,754>1,985)$ dengan nilai signifikansi $(0,000<0,05)$, sehingga dapat disimpulkan bahwa variabel promosi memiliki pengaruh yang signifikan terhadap kepuasan pelanggan pada layanan GrabFood. Artinya, semakin baik promosi yang dilakukan oleh GrabFood, maka kepuasan pelanggan pun akan semakin meningkat. Secara keseluruhan, promosi yang dilakukan dan ditawarkan oleh GrabFood kepada pelanggan melalui advertising, sales promotion, public relation, dan direct marketing sudah cukup menarik dan bervariasi. Promosi memiliki pengaruh terhadap kepuasan pelanggan pada layanan GrabFood apabila promosi yang dilakukan dan diberikan oleh GrabFood sesuai dengan harapan pelanggan, dimana melalui promosi tersebut pelanggan mengharapkan adanya manfaat yang diterima ketika pelanggan menggunakan layanan GrabFood. Manfaat yang diharapkan pelanggan terhadap promosi yang ditawarkan/diberikan oleh GrabFood dapat berupa promosi yang sesuai dengan kebutuhan pelanggan. Apabila promosi yang ditawarkan oleh GrabFood sesuai dengan kebutuhan pelanggan saat itu, maka pelanggan pun akan merasa puas ketika menggunakan layanan GrabFood.

\section{Analisis Pengaruh E-Service Quality dan Promosi Terhadap Kepuasan Pelanggan Pada Layanan GrabFood}

Berdasarkan hasil uji hipotesis secara simultan (Uji-F), variabel e-service quality dan promosi memiliki F-hitung > F-tabel $(78,660>3,09)$ dengan signifikansi $(0,000<0,05)$, maka dapat disimpulkan bahwa variabel e-service quality dan promosi memiliki pengaruh yang signifikan terhadap kepuasan pelanggan pada layanan GrabFood. Artinya, apabila perusahaan selalu meningkatkan $e$ service quality dan melakukan promosi yang menarik serta bermanfaat bagi pelanggan, maka hal tersebut secara bersama-sama dapat meningkatkan kepuasan pelanggan.

Hasil koefisien determinasi (KD) juga menunjukkan bahwa besar pengaruh e-service quality dan promosi terhadap kepuasan pelanggan sebesar $61,9 \%$ sehingga dapat disimpulkan bahwa e-service quality dan promosi memiliki pengaruh yang cukup besar terhadap kepuasan maupun ketidakpuasan pelanggan pada layanan GrabFood. Oleh karena itu, sangat penting bagi perusahaan untuk memperhatikan keluhan-keluhan pelanggan, terutama yang berkaitan dengan e-service quality dan promosi, supaya perusahaan dapat meningkatkan e-service quality serta memberikan promosi yang semakin baik dan sesuai dengan kebutuhan pelanggan sehingga perusahaan pun dapat mempertahankan kepuasan pelanggan tersebut.

\section{PENUTUP}

\section{Simpulan}

Berdasarkan hasil analisis dan pembahasan yang telah dijelaskan, dapat disimpulkan bahwa secara keseluruhan tanggapan responden terhadap variabel e-service quality, promosi dan kepuasan pelanggan berada pada kategori baik. Untuk variabel e-service quality, dimensi dengan perolehan tanggapan responden tertinggi, yaitu efficiency sebesar $83,25 \%$, dan yang terendah sebesar $71,25 \%$ pada dimensi reliability. Untuk variabel promosi, dimensi dengan nilai persentase tertinggi adalah sales promotion sebesar $79,92 \%$ dan persentase terendah ada pada dimensi direct marketing, yaitu sebesar 64\%. Kemudian untuk variabel kepuasan pelanggan, persentase tertinggi terdapat pada dimensi 
pelanggan tidak pernah mengeluh yang dengan persentase sebesar 78,4\%, sementara dimensi terendah adalah merekomendasikan jasa kepada orang lain dengan persentase sebesar 69,8\%.

Berdasarkan uji hipotesis yang telah dilakukan melalui Uji-T dan Uji-F, diketahui bahwa variabel $e$-service quality dan promosi secara parsial maupun simultan memiliki pengaruh yang positif dan signifikan terhadap kepuasan pelanggan pada layanan GrabFood. Besar pengaruh variabel $e$-service quality dan promosi terhadap kepuasan pelanggan yang diperoleh melalui uji koefisien determinasi sebesar $61,9 \%$ dan sisanya sebesar $38,1 \%$ dipengaruhi oleh variabel lain yang tidak diteliti dalam penelitian ini.

\section{Saran}

1. Disarankan agar Grab selaku pemilik layanan GrabFood untuk memperhatikan dan meningkatkan $e$ service quality, terutama pada dimensi yang mendapatkan persentase paling rendah, yaitu dimensi reliability. Disarankan agar Grab memperhatikan laporan masalah yang diberikan oleh pengguna, misalnya melalui feedback, rating, atau fitur report yang terdapat pada aplikasi supaya perusahaan dapat segera memperbaiki bugs yang menjadi penyebab error pada layanan GrabFood, yaitu dengan cara memberikan pembaharuan (update) pada aplikasi Grab untuk meningkatkan performa pada layanan GrabFood, seperti dengan memperbaiki fitur-fitur tertentu sehingga dapat membuat pelanggan merasa nyaman saat menggunakan GrabFood.

2. Grab sebaiknya meningkatkan promosi pada layanan GrabFood terutama pada dimensi yang mendapatkan persentase paling rendah, yaitu direct marketing. Disarankan agar Grab konsisten dalam melakukan pemasaran secara langsung, baik melalui aplikasi, e-mail, maupun media sosial dengan cara menampilkan konten dengan visual yang lebih menarik dan informatif ketika memberikan informasi terkait layanan GrabFood, seperti informasi mengenai promosi yang tersedia maupun informasi lainnya, sehingga dapat membuat pelanggan tertarik untuk menggunakan layanan GrabFood.

3. Grab sebaiknya memperhatikan dan meningkatkan kepuasan pelanggan GrabFood, terutama pada dimensi yang mendapatkan persentase paling rendah, yaitu merekomendasikan jasa kepada orang lain. Disarankan agar Grab selalu memberikan dan meningkatkan kualitas layanan serta promosi pada layanan GrabFood supaya pelanggan semakin puas dan yakin untuk merekomendasikan GrabFood kepada orang lain. Misalnya, dengan memberikan kemudahan kepada pelanggan untuk menentukan titik lokasi sendiri supaya lebih akurat. Disarankan juga agar Grab dapat memberikan penawaran promosi yang lebih menarik dan bervariasi, seperti dengan memberikan diskon tertentu bagi pelanggan yang sudah lama/sering menggunakan GrabFood, atau diskon khusus untuk pengguna baru GrabFood.

\section{UCAPAN TERIMAKASIH}

Terima kasih penulis sampaikan kepada kedua orang tua dan keluarga penulis yang senantiasa mendoakan dan mendukung penulis serta Ibu Pramitha Aulia selaku dosen pembimbing yang telah memberikan bimbingan, arahan, dan saran kepada penulis.

\section{DAFTAR PUSTAKA}

Anugrah, F. T. (2020). Effect of Promotion and Ease of Use on Customer Satisfaction and Loyalty on OVO Application Users. Quantitative Economics and Management Studies, Vol. 1, No. 2, hal. 44-50.

Astuti, Diah Laely. (2017). Pengaruh Bauran Pemasaran Jasa Terhadap Kepuasan Penumpang Kereta Api Serayu . Jurnal Ekonomi, Bisnis \& Entrepreneurship, Vol. 11, No. 2, Oktober, hal. 123-136.

Dianti, S. (2018). Pengaruh Harga, Pelayanan dan Promosi Terhadap Keputusan Penggunaan Jasa 
Angkutan Gojek Pada Mahasiswa Jurusan Pendidikan Ilmu Pengetahuan Sosial UIN Syarif Hidayatullah Jakarta. Jakarta: Universitas Islam Negeri Syarif Hidayatullah Jakarta, S1 Pendidikan Ilmu Pengetahuan Sosial.

Faradina, A., \& Satrio, B. (2016). Pengaruh Promosi Dan Kualitas Pelayanan Terhadap Kepuasan Pelanggan pada Rumah Cantik Alamanda. Jurnal Ilmu Dan Riset Manajemen, Vol. 5, No. 7, Juli, hal. 1-18.

Jannah, R., Mappatompo, A., \& Haanurat, I. (2019). The influence of product quality, service quality and price on customer satisfaction and loyalty. Proceeding of the 3rd International Conference on Accounting, Business \& Economics, 1(4): 201-206.

Jayani, Dwi Hadya (2021, Januari 22). Potensi Bisnis Pesan-Antar Makanan Daring Makin Besar. Diambil dari katadata.co.id. (Diakses 22 Januari 2021).

Kotler, P., dan Keller, K. (2016). Marketing Management (15th ed). Edinburgh Gate, Harlow, England: Pearson Education.

Malau, H. (2017). Manajemen Pemasaran. Bandung: CV Alfabeta.

Mediti, Oktavianus Chrisnamurti Sabda Putra (2020). Analisis Pengaruh Harga dan Kualitas Layanan Elektronik Terhadap Kepuasan Konsumen Pada Pengguna Aplikasi Shopee. Jurnal Ilmu Manajemen, Vol. 8, No. 4.

Prilano, K., Sudarso, A., \& Fajrillah (2020). Pengaruh Harga, Keamanan dan Promosi Terhadap Keputusan Pembelian Toko Online Lazada. Journal of Business and Economics Research (JBE), Vol. 1, No. 1, Februari, hal. 1-10.

Sugiyono. (2018). Metode Penelitian Kuantitatif, Kualitatif, dan R\&D. Bandung: Alfabeta.

Tjiptono, F. (2014). Pemasaran Jasa - Prinsip, Penerapan, dan Penelitian. Yogyakarta: Andi.

Tjiptono, F. \& Chandra, G. (2016). Service, Quality and Satisfaction 4th edition. Yogyakarta: Andi.

Vallery, Novita, H S. S. (2020). Effect of Price, Service Quality and Promotion on Customer Satisfaction Grab. Jurnal Mantik, 3(4): 31-38.

Widiarini, Annisa Dea (2020, 10 Maret). Berkat Digitalisasi, Semua Aktivitas Kini Berada di Genggaman. Diambil dari https://lifestyle.kompas.com. (Diakses 20 Desember 2020). 